\title{
Lung cancer incidence among Norwegian silicon carbide industry workers: associations with particulate exposure factors
}

\author{
Merete Drevvatne Bugge, ${ }^{1}$ Kristina Kjærheim ${ }^{2}$ Solveig Føreland, ${ }^{1,3}$ Wijnand Eduard, ${ }^{1}$ \\ Helge Kjuus ${ }^{1}$
}

${ }^{1}$ National Institute of Occupational Health, Oslo, Norway

${ }^{2}$ Cancer Registry of Norway, Oslo, Norway

${ }^{3}$ Department of Public Health and General Practice,

Norwegian University of Science and Technology, Trondheim, Norway

\section{Correspondence to}

Dr Merete Drevvatne Bugge, National Institute of Occupational Health, Pb. 8149 Dep, Oslo N-0033, Norway; mdb@stami.no

Accepted 18 April 2012 Published Online First 18 May 2012

\begin{abstract}
Objectives An increased lung cancer risk associated with total dust exposure in the silicon carbide (SiC) industry has previously been reported. The aim of the present study was to examine the relative importance of specific exposure factors by using a comprehensive, historic job exposure matrix based on about 8000 measurements.

Methods Cumulative exposure to total and respirable dust, respirable quartz, cristobalite, and SiC particles and SiC fibres was assessed for 1687 long-term workers employed during 1913-2003 in the Norwegian SiC industry. Standardised incidence ratios for lung cancer, with follow-up during 1953-2008, were calculated stratified by cumulative exposure categories. Poisson regression analyses were performed using both categorised and log-transformed cumulative exposure variables.
\end{abstract}

Results The lung cancer incidence was about twofold increased at the highest level of exposure to each of the exposure factors (standardised incidence ratios 1.9-2.3 for all agents). Internal analyses showed associations between exposure level and lung cancer incidence for all investigated factors, but a significant trend only for total dust and cristobalite. In multivariate analyses, cristobalite showed the most consistent associations, followed by SiC fibres.

Conclusions The results indicated that crystalline silica in the form of cristobalite was the most important occupational exposure factor responsible for lung cancer excess in the Norwegian SiC industry. SiC fibres seemed to have an additional effect.

Previous studies have shown that workers in the silicon carbide ( $\mathrm{SiC}$ ) industry have an overall increased risk of lung cancer. In a Canadian study, the standardised mortality ratio of lung cancer was 1.7 (95\% CI 1.1 to 2.5$).{ }^{1}$ Cancer incidence among Norwegian $\mathrm{SiC}$ workers is previously studied in two follow-ups, with end points 1996 and 2005, with standardised incidence ratios (SIR) of lung cancer 1.9 (95\% CI 1.5 to 2.3$)$ and 2.0 (95\% CI 1.6 to 2.4$),{ }^{2}{ }^{3}$ respectively. Exposure-response associations were found with exposure to total dust, but due to limited information about exposure to specific dust constituents further studies with more detailed job exposure information were recommended. ${ }^{13}$

Several airborne exposure factors in the $\mathrm{SiC}$ production are known or suspected lung cancer risk

\section{What this paper adds}

- Workers in the silicon carbide (SiC) industry have an increased incidence of lung cancer.

- The specific causal factors of this increase have not previously been known.

- The present study shows that exposures to cristobalite and SiC fibres seem to be the most important occupational risk factor.

- Control of the dust exposure in the SiC industry, especially in the furnace hall, is essential.

factors. Quartz and cristobalite from occupational sources are classified as carcinogenic to humans (International Agency for Research on Cancerclass 1$).{ }^{4}$ In vivo and in vitro studies have indicated that $\mathrm{SiC}$ fibres have toxicological similarities to asbestos fibres, which are known lung carcinogens. ${ }^{5}$ On the other hand, the most abundant exposure factor in the $\mathrm{SiC}$ industry, isometric $\mathrm{SiC}$ particles, has not shown carcinogenic potential in in vivo or in vitro studies. 67

The aim of this study was to examine the relative importance of the investigated exposure factors, quartz, cristobalite, $\mathrm{SiC}$ particles and $\mathrm{SiC}$ fibres, with respect to lung cancer risk in the Norwegian SiC industry, by using a comprehensive, historic job exposure matrix (JEM).

The study was approved by the Regional Committee for Medical Research Ethics South-East Norway and by the Norwegian Data Inspectorate.

\section{MATERIALS AND METHODS \\ Study cohort}

The study cohort was based on a previously established cohort in the Norwegian SiC industry. ${ }^{2}$ It consisted of 1687 men, employed in 1942 and onwards, with $\geq 3$ years employment in the Norwegian SiC industry between 1913 and 2003, and alive after 1 January 1953. The database comprised name, date of birth, the Norwegian unique 11-digit identification (ID)-number, plant affiliation, employment dates, job code(s) and smoking information. Information about smoking was collected once from the occupational health services at the plants, and the workers were classified as never-, ever-smoker or unknown. The cohort was linked with the Norwegian Cancer 
Registry to obtain cancer diagnoses and dates of diagnosis for the period 1 January 1953 to 31 December 2008, in addition to dates of death and emigration. Linkage was performed using the Norwegian unique 11-digit ID-number assigned to all Norwegian citizens alive in 1960 or born later. Before 1960, linkage was performed manually, using name and date of birth. After linkage, name and ID-number was replaced by a unique, random number. Follow-up started after 3 years of total employment, or 1 January 1953, if the 3 years' duration of employment was reached earlier. End of follow-up was date of lung cancer diagnosis, date of death or emigration, or 31 December 2008. The 1687 workers contributed 42910 person-years of follow-up to the study.

\section{SiC production}

The production of $\mathrm{SiC}$ by the Acheson method $^{8}$ was established in Norway in 1913. By this method, a mixture of quartz sand and petroleum coke is heated in open electric resistance furnaces by a graphite core. The heating process lasts approximately $48 \mathrm{~h}$, during which the temperature in the core approaches $2500^{\circ} \mathrm{C}$. Quartz will react with carbon and form $\mathrm{SiC}$ and carbon monoxide at temperatures above $1720^{\circ} \mathrm{C}$. At the end of the heating process, $\mathrm{SiC}$ is found in the region closest to the core. Further away from the core partly reacted material is found, and in the periphery, where the temperature can reach $1000^{\circ} \mathrm{C}$, no transformation takes place. $\mathrm{SiC}$ fibres are formed during the process ${ }^{9}$ and are accumulated in the intermediate region, where the partly reacted material is found. ${ }^{10}$ The unreacted and partly reacted material is removed from the crude before transport to the processing department where the $\mathrm{SiC}$ is crushed and sieved, impurities are removed, and the grains are classified into size fractions before packing. The petroleum coke contains impurities of sulphur, which is oxidised to sulphur dioxide during the furnace process, and traces of polycyclic aromatic hydrocarbons $(\mathrm{PAH})$ in varying amounts. Cristobalite, a high temperature crystalline phase of silica, is formed during the furnace process, through transformation of quartz at around $1500^{\circ} \mathrm{C}$.

\section{Exposure assessment and JEM}

Since 1967, personal total dust exposure has been measured with reference to specific job groups for routine control purposes and in connection with scientific exposure studies in the three Norwegian SiC plants. About 3300 measurements of total dust were available for reconstruction of the historical exposure levels. Based on the available total dust measurements covering the years 1967-2005, multiple linear regression models were developed for each department within each plant using a forward blockwise entry procedure. The following blocks were introduced into the model: (1) job group, (2) process related parameters, (3) 5-year periods and (4) a categorical variable accounting for the purpose of the measurement (research or compliance with occupational exposure limits). The exposure estimates were extrapolated backwards to periods without dust measurements by applying multipliers for estimated relative changes in exposure, based on information about process related changes and changes in working hours. Accordingly, estimates of total dust exposure were constructed for all job groups in the three plants and all years of production from 1913 to 2005.

In order to estimate exposure to specific agents, a large comparative study was performed in $2002-2003,{ }^{11}$ with around 700 parallel personal measurements of total dust and respirable dust, and total dust and fibres. The amounts of quartz, cristobalite and $\mathrm{SiC}$ dust in the respirable dust fraction were determined. ${ }^{11}$ This comparative study added approximately 5000 measurements to the exposure data. These measurements were used to develop linear mixed effect models estimating exposure to fibres, quartz, cristobalite, $\mathrm{SiC}$ dust and respirable dust from total dust exposure. The models were used to compute exposure estimates for the dust constituents from 1913 to 2005 based on the total dust estimates. The estimates were converted from geometric means to arithmetic means as described by Seixas et $\mathrm{al}^{12}$ and summarised in a JEM covering job groups in the three plants in the years 1913-2005. A few historical measurements of PAH existed, showing low exposure levels compared with current occupational exposure limits. PAH was therefore neither included in the measurement programme for the comparative measurement study nor in the subsequent modelling. Asbestos exposure was categorised as never-exposed/ever-exposed, and linked to job groups that had probable asbestos exposure in relevant time periods. No information about asbestos exposure outside the $\mathrm{SiC}$ industry was available. The development of the JEM is described in detail in Føreland et al (2012). ${ }^{13}$ A problem in the previous $\mathrm{JEM}^{3}$ was a high correlation between exposures to the different dust constituents, making differentiation of the effects from separate exposure factors difficult. In the present, revised JEM the correlation coefficients were moderate to low $\left(r_{\text {Pearson }} \leq 0.72\right)$ except the correlation between total and respirable dust $\left(r_{\text {Pearson }}=0.84\right) .{ }^{13}$ Some characteristics of the cohort and mean levels of the exposure factors are summarised in table 1.

\section{Cumulative exposure}

The information about employment periods and job codes for each individual in the cohort enabled a linkage with the JEM, thereby assigning individual mean exposures to total dust, respirable dust, respirable quartz, respirable cristobalite, respirable $\mathrm{SiC}$ particles and $\mathrm{SiC}$ fibres, for each year of employment in the $\mathrm{SiC}$ industry. Information on employment outside the $\mathrm{SiC}$ industry was not available. Individual cumulative exposure was summed up over all years of exposure. Cumulative exposure to each of the six exposure factors was categorised in three a priori defined groups (low, medium and high) ensuring equal numbers of person-years of follow-up in each category.

Each job code was assigned a department affiliation: 'Furnace department', including mixing of raw materials, furnace process, and removal of non-reacted and partly reacted material; 'Processing department', including refining of the $\mathrm{SiC}$ into the specific grain sizes; 'Maintenance department', including mechanics, electricians and other maintenance personnel serving all departments; and 'Other, low exposed personnel', including laboratory workers, stock-house workers and office workers. Persons with employment in more than one department, or with unknown affiliation, were allocated to a 'Mixed employment' group. To this 'Mixed employment' group the furnace department contributed 2863 years of exposure, the processing department 2692 years of exposure, the maintenance department 2171 years and the group of 'Other, low exposed' jobs 1343 years of exposure.

\section{Statistical analyses}

SIRs were calculated as the ratio between observed and expected numbers of lung cancer cases. Expected numbers were based on the national cancer incidence rates for men, summed up in 5 -year age and period groups. We performed SIR analyses of lung cancer stratified by department and by category of cumulative exposure to all exposure factors except asbestos, where a dichotomous exposure indicator was used. In order to account for the induction and latency time of lung cancer development, 
Table 1 Mean years of employment with SD, and geometric mean (GM), geometric SD (GSD) and estimated arithmetic mean (AM) of annual intensity of exposure to specific exposure factors, by department and period of employment, for 1687 male long-term Norwegian silicon carbide industry workers employed during 1913-2003

\begin{tabular}{|c|c|c|c|c|c|c|c|c|}
\hline & & \multicolumn{3}{|c|}{ Employment before 1960} & & \multicolumn{3}{|c|}{ Employment after 1959} \\
\hline & & $\overline{\text { GM }}$ & GSD & AM* $^{*}$ & & $\overline{\text { GM }}$ & GSD & AM* $^{*}$ \\
\hline Furnace department $(\mathrm{n} \dagger)$ & 232 & & & & 584 & & & \\
\hline Years of exposure (mean/SD) & $7.2(6.4)$ & & & & $9.5(7.3)$ & & & \\
\hline Respirable dust $\left(\mathrm{mg} / \mathrm{m}^{3}\right)$ & & 1.1 & 2.5 & 1.6 & & 0.55 & 2.5 & 0.84 \\
\hline Respirable quartz $\left(\mathrm{mg} / \mathrm{m}^{3}\right)$ & & 0.015 & 3.4 & 0.033 & & 0.0045 & 3.5 & 0.0096 \\
\hline Respirable cristobalite $\left(\mathrm{mg} / \mathrm{m}^{3}\right)$ & & 0.014 & 6.3 & 0.074 & & 0.0022 & 4.6 & 0.0072 \\
\hline Fibres (fibres $/ \mathrm{cm}^{3}$ ) & & 0.33 & 3.1 & 0.62 & & 0.20 & 2.6 & 0.31 \\
\hline Processing department $(\mathrm{n} \dagger)$ & 166 & & & & 537 & & & \\
\hline Years of exposure (mean/SD) & $9.4(8.3)$ & & & & $9.5(7.3)$ & & & \\
\hline Total dust $\left(\mathrm{mg} / \mathrm{m}^{3}\right)$ & & 12 & 2.1 & 16 & & 5.2 & 2.2 & 7.2 \\
\hline Respirable dust $\left(\mathrm{mg} / \mathrm{m}^{3}\right)$ & & 1.0 & 2.3 & 1.4 & & 0.60 & 2.2 & 0.82 \\
\hline Respirable quartz $\left(\mathrm{mg} / \mathrm{m}^{3}\right)$ & & 0.0056 & 2.3 & 0.0078 & & 0.0032 & 2.2 & 0.0044 \\
\hline Years of exposure (mean/SD) & $9.6(9.1)$ & & & & $10.3(7.8)$ & & & \\
\hline Total dust $\left(\mathrm{mg} / \mathrm{m}^{3}\right)$ & & 5.6 & 1.9 & 6.9 & & 3.5 & 2.1 & 4.7 \\
\hline Respirable dust $\left(\mathrm{mg} / \mathrm{m}^{3}\right)$ & & 0.55 & 1.8 & 0.65 & & 0.52 & 2.1 & 0.68 \\
\hline Respirable quartz $\left(\mathrm{mg} / \mathrm{m}^{3}\right)$ & & 0.0039 & 1.8 & 0.0046 & & 0.0035 & 2.1 & 0.0047 \\
\hline Respirable cristobalite $\left(\mathrm{mg} / \mathrm{m}^{3}\right)$ & & 0.0038 & 1.8 & 0.0046 & & 0.0018 & 2.1 & 0.0023 \\
\hline Respirable SiC $\left(\mathrm{mg} / \mathrm{m}^{3}\right)$ & & 0.17 & 1.9 & 0.20 & & 0.12 & 2.0 & 0.15 \\
\hline Fibres (fibres/ $/ \mathrm{cm}^{3}$ ) & & 0.19 & 1.9 & 0.23 & & 0.10 & 2.4 & 0.14 \\
\hline Other, low exposed (n†) & 88 & & & & 276 & & & \\
\hline Years of exposure (mean/SD) & $12.3(10.7)$ & & & & $11.6(8.7)$ & & & \\
\hline Total dust $\left(\mathrm{mg} / \mathrm{m}^{3}\right)$ & & 0.22 & 3.8 & 0.53 & & 0.11 & 3.5 & 0.24 \\
\hline Respirable dust $\left(\mathrm{mg} / \mathrm{m}^{3}\right)$ & & 0.021 & 3.7 & 0.048 & & 0.015 & 3.4 & 0.031 \\
\hline Respirable quartz $\left(\mathrm{mg} / \mathrm{m}^{3}\right)$ & & 0.00020 & 3.7 & 0.00047 & & 0.00011 & 3.4 & 0.00023 \\
\hline
\end{tabular}

${ }^{*} \mathrm{AM}$ estimated from GM and GSD, as described by Seixas et $a{ }^{12}{ }^{12}$ using the formula $\mathrm{AM}=\mathrm{GM}^{*} \exp \left(0.5(\ln \mathrm{GSD})^{2}\right)$.

$\dagger \mathrm{n}$, Number of workers. The sum of $\mathrm{n}$ is more than 1687, as each person may have been employed in several departments and in both periods.

we also included analyses with 10 and 20 years lagging of exposure. ${ }^{14}$ In this study, 10 years lagging of exposure meant that the cumulative exposure level of a certain person-year was set to the cumulative exposure level of the same person 10 years earlier. We calculated 95\% CIs for each risk estimate, assuming a Poisson distribution of the observed cases.

Poisson regression analyses were performed for comparison of lung cancer risks between departments, using the 'Other, low exposed' category as the reference group. These analyses were adjusted for age $(<55 / 55-74 / \geq 75$ years $)$ only; for age and smoking (ever-, never-, unknown); and were also performed among ever-smokers only due to the low number of lung cancer cases among never-smokers (one case) and those with unknown smoking status (three cases). Exposure-response associations were studied using Poisson regression analyses of lung cancer related to categories of exposure, adjusted for age, among eversmokers. Adjustment for period of diagnosis was not included in the final models, as inclusion of this variable did not change the estimates. Tests of trend were done by fitting a Poisson regression model for the linear effect of the exposure variables, assuming a constant increase in the log rate ratio per exposure category level. ${ }^{15}$ These analyses were also done with 10 and 20 years lagging of exposure. As an alternative to exposure lagging, Jahr's model ${ }^{16}$ (modified by Checkoway ${ }^{14}$ ) using time-weighted cumulative exposure was also applied. This model has been proposed for studying exposure-response associations with agents that are retained in active forms in the target tissues, ${ }^{14}$ and it was applied on quartz, cristobalite and fibre exposure, with and without a clearance factor assuming 10 years half-life of the investigated exposure factors.

The relative importance of the specific exposure factors cristobalite, $\mathrm{SiC}$, and $\mathrm{SiC}$ fibres was studied by constructing Poisson regression models including two or more exposure variables at a time. In order to limit the number of variables in the models, and to increase the stability of the analyses, we here used continuous exposure variables, which were justified by the monotonous increasing risk ratios of the categorised variables. Cumulative exposure to each exposure factor was log-transformed due to skewed distribution of the exposure. Correlation between exposure factors was investigated using Pearson's correlation coefficient ( $r_{\text {Pearson }}$ ) between log-transformed cumulative exposures. Correlations between the cumulative exposure factors were moderately high ( $r_{\text {Pearson }} 0.51-0.77$ ), except the correlation between quartz and cristobalite $\left(\mathrm{r}_{\text {Pearson }} 0.84\right)$, justifying analyses with $\mathrm{SiC}$ particles and fibres, and one of the crystalline silicas (cristobalite) simultaneously in the model. The relative effects of exposure factors were evaluated by studying how the effect estimate of one factor changed when a second 
factor was included in the model, and whether inclusion of a second factor contributed to a better fit of the model, according to the likelihood ratio test. These analyses were done among ever-smokers only. All $p$ values are two-sided.

All statistical analyses were performed using Stata V.11 (StataCorp LP).

\section{RESULTS}

The lung cancer risk in this cohort of long-term $\mathrm{SiC}$ workers was increased compared with the general male population (SIR 1.6, $95 \%$ CI 1.3 to 2.1, 62 cases). The risk was highest among workers in the furnace department (SIR 2.3, 95\% CI 1.5 to 3.5), and among those with employment in more than one department (mixed group; SIR 1.9, 95\% CI 1.3 to 2.9). Both among processing and maintenance workers the SIRs were 1.4 (95\% CI 0.7 to 2.7 and 0.7 to 2.6 , respectively). The SIR in the lowexposed group was 0.6 (95\% CI 0.2 to 1.9) (not shown in table). In the internal analyses, using the 'Other, low exposed' category as reference group, similar contrasts between the departments were observed (table 2). In analyses without adjustment for smoking, the incidence rate ratio (IRRs) were somewhat higher than in the smoking adjusted analyses, indicating a confounding effect of smoking on lung cancer incidence, seemingly strongest among furnace workers, who also had the highest ever-smoker percentage (76\%). The department-specific IRRs among eversmokers were almost similar to the smoking adjusted IRRs. The IRRs by smoking status gave high and unstable estimates due to the small reference group (only one lung cancer case among never-smokers) (table 2).

SIR analyses stratified by categories of cumulative exposure factors showed significantly increased risks with the highest level of all the four specific exposure factors (table 3). The risk estimates in the highest categories of cumulative exposure to all exposure factors increased when exposure was lagged 20 years. Internal analyses among ever-smokers, using the same cumulative exposure categories, gave increasing risks with increasing exposure to all exposure factors, and statistical significant tests of trend for cristobalite and total dust (table 4).

Lagging of exposure with 20 years gave significant tests of trend for all exposure factors except quartz (table 4). With 10 years lag of exposure, the results did not differ from the non-lagged analyses (not shown in table). The indicator of exposure to asbestos showed no association to lung cancer incidence (not shown in table). The 'Jahr' model with time- weighing of exposure did not give increasing risk estimates with increasing exposure levels (not shown in table). When a clearance factor assuming 10 year's half-life was added to the model, ${ }^{14}$ an exposure-response association was seen with cristobalite exposure, but no significant test of trend (not shown in table).

In Poisson regression models using log-transformed cumulative exposure, the effect estimates of the other exposure factors were substantially reduced when cristobalite was added to the model (table 5). Adding cristobalite to a model already including $\mathrm{SiC}$ gave a significant likelihood ratio test, indicating a stronger effect from cristobalite. The effect estimate of cristobalite, on the other side, was somewhat reduced, and no longer significant when fibre was included in the model. Adding fibres in a model already including $\mathrm{SiC}$ reduced the effect estimate of $\mathrm{SiC}$ and gave a significant likelihood ratio test, but somewhat weaker than cristobalite. Quartz was not included in this model because of the high correlation with cristobalite $\left(\mathrm{r}_{\text {Pearson }}=0.84\right)$ introducing collinearity. With quartz in the model the effect estimates of both cristobalite and fibre increased considerably, whereas the effect estimate of quartz was reduced to about 0.5 , indicating that the effect of both fibre and cristobalite was stronger that the effect of quartz.

\section{DISCUSSION}

We have, in this cohort of $\mathrm{SiC}$ workers, documented a 2-3 times increased risk of lung cancer associated with the highest level of cumulative exposure to all the investigated exposure factors. Applying a 20-year lag of exposure, significant exposure response trends were observed for all exposure factors except quartz. When two or more exposure factors were included in a Poisson model, lung cancer risk was most strongly associated with cristobalite exposure. An association with exposure to $\mathrm{SiC}$ fibres was also demonstrated, but this association was less marked than the cristobalite association. Exposure to quartz and $\mathrm{SiC}$ dust seemed to be of less importance.

Crystalline silica from occupational sources is classified as carcinogenic to humans (Group 1) by the International Agency for Research on Cancer 1997. ${ }^{4}$ As pointed out by McDonald and Cherry, ${ }^{17}$ several of the studies showing an excess of lung cancer associated with crystalline silica exposure were conducted in manufacturing industries, entailing high temperature processes. Cristobalite is a high temperature crystalline silica polymorph. In vivo studies have shown that cristobalite produces a more

Table 2 Observed number of cases (Obs) and incidence rate ratio (IRR) with 95\% Cls of lung cancer among 1687 male Norwegian long-term silicon carbide industry workers employed during 1913-2003 and followed up during 1953-2008, by department affiliation and adjusted for age and smoking status

\begin{tabular}{|c|c|c|c|c|c|c|c|c|c|c|c|c|}
\hline & \multicolumn{7}{|c|}{ All long-term workers } & \multicolumn{5}{|c|}{ Ever-smokers } \\
\hline & $\mathrm{n}$ & Person-years & Obs & IRR $^{*}$ & $95 \% \mathrm{Cl}$ & IRR† & $95 \% \mathrm{Cl}$ & $n$ & Person-years & Obs & IRR $\neq$ & $95 \% \mathrm{CI}$ \\
\hline \multicolumn{13}{|l|}{ Department } \\
\hline Other, low exposed & 175 & 5082 & 3 & ref & & ref & & 96 & 2960 & 3 & ref & \\
\hline Furnace & 387 & 9405 & 20 & 3.8 & 1.1 to 13 & 2.6 & 0.8 to 8.7 & 294 & 7543 & 20 & 2.5 & 0.7 to 8.4 \\
\hline Processing & 347 & 7867 & 9 & 2.1 & 0.6 to 7.8 & 1.6 & 0.4 to 5.9 & 241 & 5696 & 7 & 1.3 & 0.3 to 4.9 \\
\hline Maintenance & 313 & 8043 & 9 & 2.0 & 0.5 to 7.5 & 1.5 & 0.4 to 5.7 & 213 & 5820 & 8 & 1.4 & 0.4 to 5.4 \\
\hline Mixed & 465 & 12512 & 21 & 2.9 & 0.9 to 9.6 & 2.2 & 0.7 to 7.5 & 322 & 8695 & 20 & 2.1 & 0.6 to 7.1 \\
\hline Never-smokers & 358 & 9257 & 1 & ref & & ref & & & & & & \\
\hline Ever-smokers & 1166 & 30714 & 58 & 20.9 & 2.9 to 151 & 18.9 & 2.6 to 137 & & & & & \\
\hline Unknown smoking & 163 & 2939 & 3 & 7.6 & 0.8 to 73 & 7.3 & 0.8 to 71 & & & & & \\
\hline
\end{tabular}

*Adjusted for age $(\leq 54 / 55-74 / \geq 75$ years).

†Adjusted for age ( $\leq 54 / 55-74 / \geq 75$ years) and smoking status or department.

$\ddagger$ Ever-smokers only ( $n=1166)$, adjusted for age $(\leq 54 / 55-74 / \geq 75$ years).

ref; reference. 
Table 3 Observed number of cases (Obs) and standardised incidence ratio (SIR), with 95\% Cls of lung cancer among 1687 long-term Norwegian silicon carbide $(\mathrm{SiC})$ industry workers employed during 1913-2003 and followed up during 1953-2008, by tertiles of cumulative exposure, and with exposure lagging 0 and 20 years

\begin{tabular}{|c|c|c|c|c|c|c|c|c|c|c|}
\hline \multirow[b]{2}{*}{ Cumulative exposure } & \multicolumn{5}{|c|}{ No lag } & \multicolumn{5}{|c|}{20 years lag of exposure } \\
\hline & $\overline{\mathbf{N}}$ & Person-years & Obs & SIR & $95 \% \mathrm{Cl}$ & $\overline{\mathbf{N}}$ & Person-years & Obs & SIR & $95 \% \mathrm{Cl}$ \\
\hline \multicolumn{11}{|c|}{ Total dust $\left(\mathrm{mg} \times\right.$ years $\left./ \mathrm{m}^{3}\right)$} \\
\hline $30-87$ & 1001 & 14188 & 15 & 1.4 & 0.9 to 2.4 & 675 & 5700 & 13 & 1.5 & 0.9 to 2.6 \\
\hline $87-900$ & 671 & 14374 & 38 & 2.2 & 1.6 to 3.1 & 351 & 4867 & 26 & 3.0 & 2.0 to 4.4 \\
\hline \multicolumn{11}{|c|}{ Respirable dust $\left(\mathrm{mg} \times\right.$ years $\left./ \mathrm{m}^{3}\right)$} \\
\hline $10-87$ & 701 & 14642 & 33 & 2.0 & 1.4 to 2.9 & 342 & 4367 & 21 & 2.6 & 1.7 to 3.9 \\
\hline \multicolumn{11}{|l|}{ Quartz $\left(\mathrm{mg} \times\right.$ years $\left./ \mathrm{m}^{3}\right)$} \\
\hline $0-0.026$ & 1096 & 14286 & 11 & 1.1 & 0.6 to 1.9 & 1619 & 32564 & 29 & 1.4 & 1.0 to 2.0 \\
\hline $0.026-0.077$ & 998 & 14169 & 20 & 1.8 & 1.1 to 2.7 & 653 & 5447 & 15 & 1.8 & 1.1 to 3.0 \\
\hline $0.077-2.3$ & 668 & 14455 & 31 & 1.9 & 1.4 to 2.7 & 344 & 4899 & 18 & 2.0 & 1.3 to 3.3 \\
\hline \multicolumn{11}{|c|}{ Cristobalite $\left(\mathrm{mg} \times\right.$ years $\left./ \mathrm{m}^{3}\right)$} \\
\hline $0-0.83$ & 970 & 14111 & 14 & 1.3 & 0.7 to 2.1 & 1616 & 32293 & 27 & 1.3 & 0.9 to 1.9 \\
\hline $0.83-3.0$ & 941 & 14096 & 14 & 1.3 & 0.8 to 2.2 & 677 & 5865 & 14 & 1.6 & 0.9 to 2.7 \\
\hline $3.0-60$ & 697 & 14703 & 34 & 2.2 & 1.6 to 3.1 & 357 & 4752 & 21 & 2.6 & 1.7 to 3.9 \\
\hline \multicolumn{11}{|c|}{ Fibres $\left(\right.$ fibres $\times$ years $\left./ \mathrm{cm}^{3}\right)$} \\
\hline $0-0.50$ & 925 & 13788 & 13 & 1.2 & 0.7 to 2.1 & 1619 & 31648 & 24 & 1.2 & 0.8 to 1.8 \\
\hline $0.50-2.0$ & 1018 & 14897 & 15 & 1.3 & 0.8 to 2.2 & 682 & 6466 & 14 & 1.6 & 0.9 to 2.6 \\
\hline $2.0-93$ & 614 & 14225 & 34 & 2.2 & 1.6 to 3.0 & 336 & 4796 & 24 & 2.6 & 1.8 to 3.9 \\
\hline
\end{tabular}

rapidly developing pulmonary fibrosis ${ }^{18}{ }^{19}$ and is cleared less effectively from the airways ${ }^{20}$ than quartz. Cristobalite exposure, however, is relatively infrequent in epidemiological studies, as cristobalite is a result of quartz heating, and thus limited to special industries. Some of the epidemiological studies giving the strongest evidence for an association between crystalline silica

Table 4 Incidence rate ratios (IRR) and 95\% Cls for lung cancer among 1166 ever-smoking Norwegian long-term silicon carbide (SiC) industry workers employed during 1913-2003 and followed up during 1953-2008, by tertiles of cumulative exposure, and with exposure lagging 0 and 20 years

\begin{tabular}{|c|c|c|c|c|c|c|c|c|}
\hline & \multicolumn{4}{|c|}{ No lag } & \multicolumn{4}{|c|}{20 years lag of exposure } \\
\hline & Obs & IRR* $^{*}$ & $95 \% \mathrm{CI}$ & $\mathbf{p}_{\text {trend }}$ & Obs & IRR* $^{*}$ & $95 \% \mathrm{CI}$ & $\mathbf{p}_{\text {trend }}$ \\
\hline \multicolumn{9}{|c|}{ Total dust $\left(\mathrm{mg} \times\right.$ years $\left./ \mathrm{m}^{3}\right)$} \\
\hline $30-87$ & 13 & 1.0 & 0.4 to 2.4 & & 12 & 1.4 & 0.7 to 3.0 & \\
\hline $87-900$ & 36 & 1.9 & 0.9 to 4.0 & $\mathrm{p}=0.04$ & 25 & 3.0 & 1.6 to 5.6 & $\mathrm{p}=0.001$ \\
\hline \multicolumn{9}{|c|}{ Respirable dust $\left(\mathrm{mg} \times\right.$ years $/ \mathrm{m}^{3}$ ) } \\
\hline $10-87$ & 32 & 2.0 & 0.9 to 4.4 & $\mathrm{p}=0.09$ & 21 & 2.4 & 1.3 to 4.6 & $\mathrm{p}=0.007$ \\
\hline \multicolumn{9}{|c|}{ Quartz $\left(\mathrm{mg} \times\right.$ years $\left./ \mathrm{m}^{3}\right)$} \\
\hline $0-0.026$ & 10 & 1.0 & & & 25 & 1.0 & & \\
\hline $0.026-0.077$ & 18 & 1.3 & 0.6 to 2.8 & & 16 & 1.5 & 0.8 to 2.9 & \\
\hline $0.077-2.3$ & 30 & 1.5 & 0.7 to 3.1 & $\mathrm{p}=0.3$ & 17 & 1.5 & 0.8 to 2.8 & $\mathrm{p}=0.2$ \\
\hline \multicolumn{9}{|c|}{ Cristobalite $\left(\mathrm{mg} \times\right.$ years $\left./ \mathrm{m}^{3}\right)$} \\
\hline $0-0.83$ & 14 & 1.0 & & & 26 & 1.0 & & \\
\hline $0.83-3.0$ & 12 & 0.7 & 0.3 to 1.5 & & 11 & 1.0 & 0.5 to 2.1 & \\
\hline $3.0-60$ & 32 & 1.4 & 0.7 to 2.6 & $\mathrm{p}=0.2$ & 21 & 2.2 & 1.2 to 4.1 & $\mathrm{p}=0.02$ \\
\hline \multicolumn{9}{|c|}{ Fibres $\left(\right.$ fibres $\times$ years $/ \mathrm{cm}^{3}$ ) } \\
\hline $0-0.50$ & 11 & 1.0 & & & 21 & 1.0 & & \\
\hline $0.50-2.0$ & 14 & 1.0 & 0.5 to 2.2 & & 14 & 1.4 & 0.7 to 2.9 & \\
\hline $2.0-93$ & 33 & 1.7 & 0.8 to 3.3 & $\mathrm{p}=0.1$ & 23 & 2.3 & 1.2 to 4.4 & $\mathrm{p}=0.009$ \\
\hline
\end{tabular}

*Adjusted for age $(0-54 / 55-74 / \geq 75)$.

Obs, observed number of cases. 
Table 5 Incidence rate ratios (IRR) and 95\% Cls for lung cancer related to log-transformed cumulative exposure to cristobalite, SiC fibres and SiC particles among 1166 male ever-smoking Norwegian long-term SiC industry workers employed during 1913-2003 and followed up during 1953-2008, adjusted for age and the other exposure factors

\begin{tabular}{|c|c|c|c|c|c|}
\hline & \multicolumn{5}{|c|}{ Smokers, $N=1166,30714$ PYR, 58 cases } \\
\hline & IRR & $95 \% \mathrm{Cl}$ & LR-test* & AIC & $\overline{r_{\text {Pearson }} \dagger}$ \\
\hline Cristobalite & 1.9 & 1.2 to 2.9 & & 275.6 & \\
\hline Cristobalite adjusted for SiC & 2.0 & 1.2 to 3.3 & $\mathrm{p}=0.8$ & 277.5 & 0.74 \\
\hline Cristobalite adjusted for $\mathrm{SiC}$ and fibres & 1.6 & 0.8 to 3.3 & $\mathrm{p}=0.4$ & 278.8 & \\
\hline Cristobalite adjusted for fibres & 1.5 & 0.8 to 2.9 & $\mathrm{p}=0.4$ & 276.9 & 0.76 \\
\hline Cristobalite adjusted for fibres and SiC & 1.6 & 0.8 to 3.3 & $\mathrm{p}=0.8$ & 278.8 & \\
\hline Fibres & 1.9 & 1.2 to 2.9 & & 276.7 & \\
\hline Fibres adjusted for $\mathrm{SiC}$ & 1.7 & 1.1 to 2.9 & $\mathrm{p}=0.6$ & 278.4 & 0.51 \\
\hline Fibres adjusted for $\mathrm{SiC}$ and cristobalite & 1.3 & 0.7 to 2.6 & $\mathrm{p}=0.2$ & 278.8 & \\
\hline Fibres adjusted for cristobalite & 1.3 & 0.7 to 2.6 & $\mathrm{p}=0.2$ & 276.9 & 0.76 \\
\hline Fibres adjusted for cristobalite and SiC & 1.3 & 0.7 to 2.6 & $\mathrm{p}=0.8$ & 278.8 & \\
\hline $\mathrm{SiC}$ & 1.4 & 1.0 to 2.1 & & 281.4 & \\
\hline SiC adjusted for fibres & 1.1 & 0.7 to 1.8 & $p=0.03$ & 278.4 & 0.51 \\
\hline SiC adjusted for fibres and cristobalite & 0.9 & 0.5 to 1.6 & $\mathrm{p}=0.2$ & 278.8 & \\
\hline SiC adjusted for cristobalite & 0.9 & 0.5 to 1.6 & $p=0.02$ & 277.5 & 0.74 \\
\hline SiC adjusted for cristobalite and fibres & 0.9 & 0.5 to 1.6 & $\mathrm{p}=0.4$ & 278.8 & \\
\hline
\end{tabular}

*LR-test: Likelihood ratio test comparing the actual model with the model containing one less exposure factor.

$+r_{\text {Pearson: }}$ Pearson's correlation coefficient.

PYR, person - years; AIC, Akaike's Information Criterion; SiC, silicon carbide.

exposure and lung cancer are studies from the diatomaceous earth industry, where cristobalite is the most abundant crystalline silica polymorph. ${ }^{21}$ The highest exposed workers in our study had cumulative respirable cristobalite exposure estimates of $0.093-2.7 \mathrm{mg} \times$ years $/ \mathrm{m}^{3}$, whereas the mean intensity of respirable cristobalite exposure in the furnace hall before 1960 was estimated to have been $0.074 \mathrm{mg} / \mathrm{m}^{3}$. Very few other studies have reported the levels of exposure to cristobalite. Rafnsson and Gunnarsdóttir reported respirable cristobalite exposure levels of $0.03-0.7 \mathrm{mg} / \mathrm{m}^{3}$ in the Icelandic diatomaceous earth industry, but did not report cumulative exposure levels. ${ }^{22}$ Rice et al reported mean cumulative levels of $2.2 \mathrm{mg} \times$ years $/ \mathrm{m}^{3}$ respirable crystalline silica (maximum cumulative level $63 \mathrm{mg} \times$ years $/ \mathrm{m}^{3}$ ) in the diatomaceous earth industry. ${ }^{23}$ Compared with these two studies, the historical cristobalite exposure levels estimated in our study was relatively low. Due to high correlation between cristobalite and quartz estimates, it was not possible in this study to separate the effect of quartz from the effect of cristobalite. However, it seems clear that cristobalite was the stronger factor of the two.

Since $\mathrm{SiC}$ fibres (whiskers) were introduced as strengthening material in ceramics, several in vivo and in vitro studies have been performed in order to determine the toxicological importance of these fibres. This interest was amplified after SiC fibres were discovered as part of the working atmosphere in the furnace hall of the $\mathrm{SiC}$ producing industry. ${ }^{9}$ So far, studies have shown that $\mathrm{SiC}$ fibres have similarities with asbestos fibres, both with respect to direct cell toxicity ${ }^{24}$ and with respect to biopersistence. ${ }^{25}$ The results of the previous Norwegian SiC lung cancer study indicated that there could be an exposure-response association with $\mathrm{SiC}$ fibres, but the exposure data were too sparse to draw any firm conclusions. ${ }^{3}$ In the exposure assessment study which forms the basis of the JEM, SiC fibres were measured in parallel with total dust, giving job group specific estimates of $\mathrm{SiC}$ fibre exposure relative to total dust exposure. ${ }^{11}$ Although fibres had a stronger association with lung cancer than quartz and $\mathrm{SiC}$, this effect was somewhat reduced when cristobalite was included in the multivariate model. However, the effect estimate (IRR) of $\mathrm{SiC}$ fibres after inclusion of cristobalite and $\mathrm{SiC}$ particles in a multivariate model was still 1.3, and we cannot from this study exclude an effect of $\mathrm{SiC}$ fibre exposure on lung cancer incidence.

The exposure assessment study does not take into account the use of personal protective equipment (PPE) due to limited information about historical use of respirators. Such information was available only for $16 \%$ of the measurements before 2002 . In the $2002 / 2003$ investigation, $26 \%$ of the workers reported no use of PPE and $61 \%$ used PPE some of the time. ${ }^{11}$ Plant personnel were interviewed on historical use of PPE, and they informed that the use was infrequent in earlier years, and that the compliance is better now. Not adjusting for the use of respirators might thus lead to an overestimation of the inhaled dose, especially for the recent years. This again might lead to an underestimation of the exposure-response relation in the epidemiological analyses, but as all the lung cancer cases had their first employment before 1981, this underestimation is assumed to be minor.

The information about smoking habits in the present study is limited to ever-smokers/never-smokers and unknown. In order to adjust for the well-known effect of smoking on lung cancer risk, we chose to perform the more advanced analyses on the subcohort of ever-smokers. By using the subcohort of eversmokers in the IRR analyses at department level we got approximately the same risk estimates as when we adjusted for smoking. The advantage of limiting the analyses to ever-smokers was to obtain a better balance in the data, with less risk of collapse of the analyses due to few cases in some of the groups. A high correlation between intensity of smoking and degree of dust exposure could still give a possible bias, but this question could not be addressed with the information available in this study. Neither could the question of effect modification by smoking be addressed due to very few lung cancer cases in the never-smoker group.

Potential exposure to other carcinogenic agents, such as asbestos and PAHs, should also be considered. We had in this study only qualitative information about asbestos exposure based on the plant personnel's knowledge about asbestos use in earlier times. ${ }^{13}$ Using an indicator of ever-exposure to asbestos, we found no evidence for an association with lung cancer incidence. The fact that the incidence of mesothelioma was at the 
level of the general population ${ }^{2}$ also indicates that asbestos exposure has not been of great relevance in this industry. Only a few measurements of PAHs have been performed in the Norwegian $\mathrm{SiC}$ industry, and the main part of these show low exposure levels, except in measurements related to crane operators prior to the introduction of fresh air ventilated crane cabins. Only one of the lung cancer cases in our study worked as a crane operator in this period. The mean of other measurements in the furnace hall was $1.0 \mu \mathrm{g} / \mathrm{m}^{3}$, compared with the Norwegian occupational exposure limit of $40 \mu \mathrm{g} / \mathrm{m}^{3}$. This, in addition to the fact that other cancers associated with PAH exposure, such as bladder cancer, was not increased in the $\mathrm{SiC}$ industry ${ }^{2}$ indicates that other factors than PAH were the more important carcinogenic agents.

As lung cancer develops slowly, with $10-20$ years induction and latency time, exposure lagging is frequently used in order to weight the assumed aetiologically most important exposures most heavily. ${ }^{14}$ Lagging of exposure with 10 and 20 years implies that each person-year of follow-up is assigned a cumulative level of exposure corresponding to the cumulative level 10 or 20 years earlier. The 10 years lagging gave no other results than the nonlagged analyses, whereas with 20 years lagging of exposure more significant exposure-response associations were seen, indicating a longer induction and latency period than 10 years. In order to study the effect of slow clearance of deposited particles and fibres from the lung, we also applied a model of time-weighted exposure. In this Jahr model, exposures are weighted relative to the number of years since exposure. These analyses did not show any exposure-response associations, in contrast to the analyses with 20 years lag. The results are difficult to interpret, but we might speculate that the Jahr model gives an overcorrection for the time factor in this context. The model was originally applied for latency consideration related to silicosis, and its relevance to carcinogenesis remains unclear.

In Poisson regression analyses the question of overdispersion should be considered. We assume that there is no dependency between the lung cancer cases giving clusters. However, in order to evaluate the fit of the models, we performed the Poisson analyses (tables 2, 4 and 5) using the option of robust SE. These analyses gave only marginal adjustments of the CIs and no changes in the effect estimates or significance levels. We have therefore chosen to use the unadjusted numbers in the tables.

\section{CONCLUSION}

We have found a 2-3 times increased risk of lung cancer associated with the highest level of cumulative exposure to quartz, cristobalite, $\mathrm{SiC}$ particles and $\mathrm{SiC}$ fibres among workers in the Norwegian SiC industry compared with the general male population. Internal analyses using multivariate models indicated that cristobalite was the most important occupational risk factor, but exposure to $\mathrm{SiC}$ fibres also appeared to contribute to the increased lung cancer risk. Exposure to quartz and $\mathrm{SiC}$ particles was not seen to influence the lung cancer incidence.

Acknowledgements The authors thank Jan Ivar Martinsen for his help with linking the Cancer Registry data and the JEM.

Contributors MDB updated the Norwegian silicon carbide industry cohort with employment periods and new employees in the period 1997-2003. She contributed to the development of the job coding system. She performed all the statistical analyses and wrote the paper. KK was cosupervisor on the project, with expertise on register studies of cancer and mortality. She read and commented on the manuscript. SF collected all the historical exposure data and performed new measurements of exposure. She contributed to the development of the job coding system. She constructed the job exposure matrix used in the epidemiological analyses. She read and commented on the manuscript. WE was cosupervisor on the project, with expertise on exposure related epidemiological analyses. He supervised the analyses, read and commented on the manuscript. HK was the main supervisor on the project. He supervised the epidemiological analyses, and read and commented on the manuscript.

Funding The research has been supported with the aid of EXTRA funds from the Norwegian Foundation for Health and Rehabilitation, and with grants from the Norwegian Ministry of Labour.

Competing interests None declared

Ethics approval The ethics approval was provided by Regional Committee for Medical Research Ethics South-East Norway, Oslo.

Provenance and peer review Not commissioned; externally peer reviewed.

\section{REFERENCES}

1. Infante-Rivard C, Dufresne A, Armstrong B, et al. Cohort study of silicon carbide production workers. Am J Epidemiol 1994;140:1009-15.

2. Bugge MD, Kjuus H, Martinsen Jl, et al. Cancer incidence among short- and longterm workers in the Norwegian silicon carbide industry. Scand J Work Environ Health 2010; $36: 71-9$

3. Romundstad $\mathbf{P}$, Andersen A, Haldorsen T. Cancer incidence among workers in the Norwegian silicon carbide industry. Am J Epidemiol 2001;153:978-86.

4. International Agency for Research on Cancer. Silica, some silicates, coal dust and para-amid fibrils. IARC Monogr Eval Carcinog Risks Hum 1997:68:204-11.

5. Vaughan GL, Trently SA. The toxicity of silicon carbide whiskers, a review. J Environ Sci Health A Environ Sci Eng Toxic Hazard Subst Control 1996:31:2033-54.

6. Bruch J, Rehn B, Song $H$, et al. Toxicological investigations on silicon carbide. 1. Inhalation studies. Br J Ind Med 1993:50:797-806.

7. Bruch J, Rehn B, Song W, et al. Toxicological investigations on silicon carbide. 2 In vitro cell tests and long term injection tests. Br J Ind Med 1993;50:807-13.

8. Liethschmidt K. Silicon carbide. Ullmann's Encyclopedia of Industrial Chemistry. Vol. A 23. Weinheim, Germany: VCH Verlagsgesellshaft mbH, 1993:749-58.

9. Bye E, Eduard W, Gjønnes J, et al. Occurrence of airborne silicon carbide fibers during industrial production of silicon carbide. Scand J Work Environ Health 1985;11:111-15

10. Gunnæs AE, Olsen A, Skogstad A, et al. Morphology and structure of airborne betaSiC fibres produced during the industrial production of non-fibrous silicon carbide. $J$ Materials Sci 2005:40:6011-17.

11. Føreland S, Bye E, Bakke B, et al. Exposure to fibres, crystalline silica, silicon carbide and sulphur dioxide in the norwegian silicon carbide industry. Ann Occup Hyg 2008; 52:317-36.

12. Seixas NS, Robins TG, Moulton LH. The use of geometric and arithmetic mean exposures in occupational epidemiology. Am J Ind Med 1988;14:465-77.

13. Foreland S, Bugge MD, Bakke B, et al. A novel strategy for retrospective exposure assessment in the Norwegian silicon carbide industry. J Occup Environ Hyg 2012;9:230-41.

14. Checkoway $\mathbf{H}$, Pearce $\mathrm{N}$, Hickey $\mathrm{JL}$, et al. Latency analysis in occupational epidemiology. Arch Environ Health 1990;45:95-100.

15. Kirkwood BR, Sterne JAC. Essential Medical Statistics. 2nd edn. Malden, Massachusetts: Blackwell Science, 2006:249-62.

16. Jahr J. Dose-response basis for settling a quartz threshold limit value: a new, simple formula for calculating the "lifetime dose" of quartz. Arch Environ Health 1974:29:338-40

17. McDonald C, Cherry N. Crystalline silica and lung cancer: the problem of conflicting evidence. Indoor Built Environ 1999;8:121-6.

18. King EJ, Mohanty GP, Harrison CV, et al. The action of different forms of pure silica on the lungs of rats. Br J Ind Med 1953;10:9-17.

19. Hemenway DR, Absher M, Landesman $\mathrm{M}$, et al. Differential lung response following silicon dioxide polymorph aerosol exposure. In: Goldsmith DF, Winn DM, Shy CM, eds. Silica, Silicosis, and Cancer. Controversy in Occupational Medicine. New York, NY: Praeger, 1986:105-16.

20. Hemenway DR, Absher MP, Trombley L, et al. Comparative clearance of quartz and cristobalite from the lung. Am Ind Hyg Assoc J 1990;51:363-9.

21. Checkoway H, Heyer NJ, Demers PA, et al. Mortality among workers in the diatomaceous earth industry. Br J Ind Med 1993;50:586-97.

22. Rafnsson V, Gunnarsdóttir H. Lung cancer incidence among an Icelandic cohort exposed to diatomaceous earth and cristobalite. Scand J Work Environ Health 1997;23:187-92

23. Rice FL, Park R, Stayner L, et al. Crystalline silica exposure and lung cancer mortality in diatomaceous earth industry workers: a quantitative risk assessment. Occup Environ Med 2001;58:38-45

24. Stanton MF, Layard M, Tegeris A, et al. Relation of particle dimension to carcinogenicity in amphibole asbestoses and other fibrous minerals. J Natl Cancer Inst 1981;67:965-75.

25. Searl A, Buchanan D, Cullen RT, et al. Biopersistence and durability of nine minera fibre types in rat lungs over 12 months. Ann Occup Hyg 1999;43:143-53. 